\title{
Broad autism phenotype features of Chinese parents with autistic children and their associations with severity of social impairment in probands
}

Li-Juan Shi $^{1 \dagger}$, Jian-Jun Ou ${ }^{1 \dagger}$, Jing-Bo Gong ${ }^{1,2}$, Su-Hong Wang ${ }^{1,3}$, Yuan-Yue Zhou ${ }^{1,4}$, Fu-Rong Zhu' ${ }^{1}$ Xu-Dong Liu ${ }^{5}$, Jing-Ping Zhao ${ }^{1}$ and Xue-Rong Luo ${ }^{1 *}$

\begin{abstract}
Background: Parents of children with autism have higher rates of broad autism phenotype (BAP) features than parents of typically developing children (TDC) in Western countries. This study was designed to examine the rate of BAP features in parents of children with autism and the relationship between parental BAP and the social impairment of their children in a Chinese sample.

Methods: A total of 299 families with autistic children and 274 families with TDC participated in this study. Parents were assessed using the Broad Autism Phenotype Questionnaire (BAPQ), which includes self-report, informant-report, and best-estimate versions. Children were assessed using the Chinese version of the Social Responsiveness Scale (SRS).

Results: Parents of children with autism were significantly more likely to have BAP features than were parents of TDC; mothers and fathers in families with autistic children had various BAP features. The total scores of the informant and best-estimate BAPQ versions for fathers were significantly associated with their children's SRS total scores in the autism group, whereas the total scores of the three BAPQ versions for mothers were significantly associated with their children's SRS total scores in the TDC group. In the autism group, the total SRS scores of children with "BAP present" parents (informant and best-estimate) were higher than the total SRS scores of children with"BAP absent" parents. In the TDC group, the total SRS scores of children with "BAP present" parents were higher than the total SRS scores of children with"BAP absent" parents (best-estimate).

Conclusions: Parents of autistic children were found to have higher rates of BAP than parents of TDC in a sample of Chinese parents. The BAP features of parents are associated with their children's social functioning in both autism families and TDC families, but the patterns of the associations are different.
\end{abstract}

Keywords: Broad autism phenotype, Parent, Autism, Social Adjustment, Chinese

\section{Background}

Autism is a neurodevelopmental disorder marked by early-onset impairments in social interaction and communication, and unusually restricted, repetitive behavior and interests [1]. Autism has a strong genetic influence, with heritability estimates exceeding $80 \%$ [2]. However,

\footnotetext{
*Correspondence: luoxr@vip.sina.com

${ }^{\dagger}$ Equal contributors

'Mental Health Institute of the Second Xiangya Hospital and Key Laboratory of Psychiatry and Mental Health of Hunan Province, The Central South

University, 139 Middle Renmin Road, Changsha, Hunan, PR China

Full list of author information is available at the end of the article
}

environmental risks and the gene-environment interplay in the etiology of autism are important for interpreting this heritability, which is never $100 \%$. Identification of autism susceptibility loci is complex and heterogeneous, with up to 1000 genes being implicated [3, 4]. Many genetic variants that are linked to autism have a high degree of pleiotropy (i.e., one gene affects more than one phenotype). To understand the genetic etiology of autism better, some researchers have turned their attention to the milder expression of autistic traits in parents 
or siblings of individuals with autism, which are referred to as the broad autism phenotype (BAP).

BAP is a term describing a group of mild, non-pathological social dysfunctions, communication traits, and unusual personality features that can often be found in the relatives of individuals with autism $[5,6]$. Thus, BAP is thought to reflect a genetic propensity for the disorder. Studies on BAP would be helpful to identify which traits aggregate in family members and are, therefore, useful for restricting phenotypic heterogeneity to detect vulnerability genes for autism more accurately. Researchers from fields of autism genetics $[7,8]$ and behavioral genetics $[9,10]$ have strongly recommended such an approach. Prevalence estimates indicate that $14 \%$ to $50 \%$ of family members of individuals with autism exhibit at least one BAP feature [11-13], and some studies have explored the relationship between parental BAP and child social function. Sasson et al. [14] who classified the parents of autistic probands into "BAP present" and "BAP absent," found that children of "BAP present" parents had higher scores on the Social Communication Questionnaire (SCQ) than those of "BAP absent" parents. Similarly, Maxwell et al. [15] reported that paternal BAP scores significantly correlated with the Social Responsiveness Scale (SRS) scores of their children with autism spectrum disorder. The SCQ and the SRS are commonly used measures of autism.

Although several Western studies have examined the rate of BAP traits in parents with autistic children [11-13, 15], little research has been conducted on this association in China. Cultural differences between China and Western counties might affect the rate of BAP traits in Chinese parents of children with autism. Since the parenting style and family interaction pattern in China are different from those in Western countries, these differences also might affect the association between parental BAP traits and the child's social function. Therefore, we designed the present study to explore the rate of BAP in Chinese parents with autistic children, and to explore how parental BAP features are associated with the severity of autism symptoms in probands.

\section{Methods}

\section{Participants}

The research protocol for this study was approved by the ethics committee of the Second Xiangya Hospital, Central South University, China. Written informed consent was obtained from all the parents.

Autism families were recruited from special education schools, which provide interventions for children with autism. The families of typically developing children were randomly recruited from two kindergartens in the same city. The inclusion criteria for parents were their written consent to participate, intact families (biological parents still married and living together), with a child living with both parents. The exclusion criteria for parents were severe medical or genetic conditions, history of psychiatric disorders (e.g., autism, developmental disorder, depression, or schizophrenia) or any hearing/vision impairments (other than prescription glasses). Parents of typically developing children also had to have no history of autism or any related developmental disorders in firstdegree relatives.

Children with autism had a previous DSM-IV diagnosis of autism made by a licensed clinician experienced in the assessment and diagnosis of autism. Typically developing children who were reported to have developmental disorders and related medical problems (e.g., epilepsy or head injury) were excluded.

A total of 324 families of children with autism and 354 families of typically developing children were recruited for the study from September 2012 to January 2015. Twentyfive families of autistic children and 56 families of typically developing children were excluded because of missing data. Another 24 families of typically developing children were excluded from all the analyses because the children had excessively high total raw scores on the SRS, since a child with a SRS total raw score exceeding 65 may have social problems [16]. This yielded a final sample of 299 families of autistic children and 274 families of typically developing children (Table 1).

The children ranged in age from 28 months through 155 months. There was no difference in age between the two groups (autism: $M=59.60$ months; typically developing children: $\mathrm{M}=58.63$ months).

\section{Measurement of parental BAP}

The Broad Autism Phenotype Questionnaire (BAPQ) [17] was used to measure parental BAP features. It is a reliable screening tool for detecting BAP in adults, which assesses particular personality and language characteristics along three dimensions - Aloof personality, Rigid personality, and Pragmatic language. All parents were asked to complete the self-report version of the BAPQ, independently, as well as the informant version about their spouse. The BAPQ was presented to them as "The Personality and Preferences Questionnaire" in order to reduce bias associated with beliefs about autism. The validity of the Chinese version of the BAPQ was verified, with the permission of its author (Professor Joseph Piven: Department of Psychiatry, Neurodevelopmental Disorders Research Center, University of North Carolina), by translating it into Chinese, verifying the Chinese version by translating it back to English, and then comparing that version with the original version. Three sets of scores were obtained for each parent: self-report BAPQ scores, informant-report BAPQ scores, and best-estimate scores (the average of the self-report and informant-report scores). We adopted the cutoff values established by Sasson et al. [13] to reduce 
Table 1 Demographic Information

\begin{tabular}{|c|c|c|c|c|}
\hline & PCA $(n=299)$ & PTC $(n=274)$ & $t / x^{2}$ & $p$ value \\
\hline & Mean or N (SD or \%) & Mean or N (SD or \%) & & \\
\hline Age of child, Months & $59.60(14.89)$ & $58.63(15.14)$ & -0.771 & 0.441 \\
\hline Gender of child, N (\%) & & & 97.10 & $<0.001$ \\
\hline Boys & $258(86.3 \%)$ & $131(47.8 \%)$ & & \\
\hline Girls & $41(13.7 \%)$ & $143(52.2 \%)$ & & \\
\hline Child's SRS total score & $98.93(25.35)$ & 43.23(11.29) & -30.532 & $<0.001$ \\
\hline Age of father, Years & $35.07(3.80)$ & $34.97(3.94)$ & -0.318 & 0.751 \\
\hline Age of mother, Years & $32.88(3.42)$ & $32.60(3.40)$ & -0.973 & 0.331 \\
\hline Education of father, N (\%) & & & 14.610 & 0.001 \\
\hline Primary to junior high school & $29(9.7 \%)$ & $58(21.1 \%)$ & & \\
\hline High school to some college & $146(48.9 \%)$ & $116(42.4 \%)$ & & \\
\hline Undergraduate or above & $124(41.4 \%)$ & $100(36.5 \%)$ & & \\
\hline Education of mother, $\mathrm{N}(\%)$ & & & 19.522 & $<0.001$ \\
\hline Primary to junior high school & $43(14.4 \%)$ & $81(29.5 \%)$ & & \\
\hline High school to some college & $139(46.5 \%)$ & $102(37.2 \%)$ & & \\
\hline Undergraduate or above & $117(39.1 \%)$ & $91(33.3 \%)$ & & \\
\hline Family income (Yuan) & & & 44.487 & $<0.001$ \\
\hline Less than 30,000 & $57(19.1 \%)$ & $35(12.8 \%)$ & & \\
\hline 30,000 -less than 50,000 & $93(31.1 \%)$ & $41(15 \%)$ & & \\
\hline 50,000 -less than 70,000 & $48(16.1 \%)$ & $34(12.4 \%)$ & & \\
\hline 70,000 -less than 100,000 & $43(14.4 \%)$ & $53(19.3 \%)$ & & \\
\hline More than 100,000 & $58(19.4 \%)$ & $111(40.5 \%)$ & & \\
\hline
\end{tabular}

PCA: parents of children with autism; PTC: parents of typically developing children. SRS: Social Responsiveness Scale. Sixty-three children with autism and sixtythree typically developing children who were younger than four 4 years old, were excluded from the analyses of SRS scores. Family income: according to the annual per capita income statistics published by the statistics for Hunan province in 2011.

false positives and to optimize the diagnostic classification of the BAP.

\section{Measurement of children's social impairment}

The Chinese version of the Social Responsiveness Scale (SRS) [16] was used to measure the social impairment of the children. The original SRS, which was developed by Constantino and colleagues in 2002 [18, 19], is a 65-item self-report or caregiver-report questionnaire for 4-18 years old children, that uses a 4-point Likert-type scale. The SRS, which was completed by the mothers in this study, can be used as a screening tool, as well as an aid for clinical diagnosis. It has subscale scores for specific symptom domains (Social awareness, Social cognition, Social communication, Social motivation, and Autistic mannerisms), and a total score that serves as an index of the severity of social deficits. A higher total SRS score indicates greater severity of social impairment. The SRS is applicable to all participants - not only those with autism - and it is not affected by intelligence, age, race, or the education level of respondents $[18,20]$. The Chinese version of the SRS has fair test-retest reliability (intraclass correlations 0.751-0.852), internal consistency (Cronbach's alpha
0.944-0.947), and convergent validity (Pearson's correlations $0.609-0.865)$ [16].

\section{Statistical analysis}

Data analysis was performed using SPSS version 17. All statistical tests were 2-tailed using 0.05 as the level of statistical significance. Continuous variables are described using means and standard deviations (SD), whereas categorical variables are reported using frequencies and percentages. Between-group comparisons were performed using independent $\mathrm{t}$-tests or analysis of variance (ANOVA) for continuous variables, and the Chi-square $\left(x^{2}\right)$ test or Fisher's exact probability test for categorical variables.

Multivariate analysis of variance (MANOVA) was performed to compare the BAPQ scores between the two parent groups. In this model, the dependent variables were self-report, informant-report, and best-estimate Aloof personality, Pragmatic language, and Rigidity subscales, and the total scores. The between-subject factors were group (PCA vs. PTC) and sex (father vs. mother).

Parents were then categorized as "BAP present" or "BAP absent," based on whether the BAPQ self-report, informant-report, and best-estimates for the total score 
or any subscale scores exceeded the cutoff values reported by Sasson et al. (2013) [13]. Chi-square or Fisher's tests were conducted to determine whether the frequency of BAP features of parents (i.e. the proportion of "present" cases) differed between families of autistic and typically developing children.

To determine if different BAP features co-occur more frequently in parents of children with autism than in parents of typically developing children, the dichotomized "present" scores on each of the three subscales and the total score were summed to indicate the number of BAP features a parent had: 0, 1, 2, 3, 4 (For example, a "3" indicates that a parent had three distinct BAP features.). The proportion of parents with different numbers of BAP features were compared between the groups.

Linear regression analyses were performed to examine whether the BAPQ total scores of parents were associated with the severity of social impairment (SRS) in their children. Paternal and maternal BAPQ total scores were entered in the regression model with child SRS score as the dependent variable. Independent sample t-tests were performed on the SRS total scores between children whose parents were "BAP present" or "BAP absent," separately for the autism group and the typical development group.

\section{Results}

Parents' ages were not significantly different between the autism group and typical development group. The education levels of the parents of children with autism were significantly higher than those of parents of typically developing children, but the family income of parents of children with autism was lower than that of parents of typically developing children (Table 1).

\section{BAPQ scores}

Descriptive data for the self-report, informant-report, and best-estimate BAPQ scores of the mothers and fathers in the PCA and PTC groups are presented in Table 2. MANOVA indicated there was a significant main effect of group on self-report, informant-report, and best-estimate Aloof personality subscales, the Pragmatic language subscales, and their total scores, with the parents of children with autism scoring higher than the PTC parents. There also was a significant main effect of sex on the informantreport Pragmatic language subscale, and the total score, and on the best-estimate Rigidity subscale, with mothers scoring higher than fathers. There was no significant interaction between group and sex on the BAPQ scores (See Table 2). Nor did the scores of fathers and mothers within PCA's differ significantly on any of three versions of the subscales of the BAPQ (all $p$ 's $\geq 0.05$ ).

\section{BAP features frequency}

Parents of children with autism had significantly higher rates of BAP features than the parents of typically developing children, except for the self-report Pragmatic language subscale and the informant-report and bestestimate Rigidity subscales for mothers, and the self-report and best-estimate Rigidity subscales and informant-estimate Aloof personality subscale for fathers (Table 3). Among the

Table 2 Mean BAPQ scores of the two parental groups

\begin{tabular}{|c|c|c|c|c|c|c|c|}
\hline & \multicolumn{2}{|l|}{ Fathers } & \multicolumn{2}{|l|}{ Mothers } & \multirow{3}{*}{$\begin{array}{l}F^{1}(1,1142) \\
\text { Main effect } \\
\text { for sex }\end{array}$} & \multirow{3}{*}{$\begin{array}{l}F^{2}(1,1142) \\
\text { Main effect } \\
\text { for group }\end{array}$} & \multirow{3}{*}{$\begin{array}{l}F^{3}(1,1142) \\
\text { Main effect } \\
\text { for sex } \times \text { group }\end{array}$} \\
\hline & PCA & PTC & PCA & PTC & & & \\
\hline & Mean (SD) & Mean (SD) & Mean (SD) & Mean (SD) & & & \\
\hline \multicolumn{8}{|l|}{ Self-report BAPQ } \\
\hline Aloof personality & $2.96(0.82)$ & $2.74(0.74)$ & $2.88(0.74)$ & $2.74(0.66)$ & 0.943 & $15.684^{* *}$ & 0.93 \\
\hline Pragmatic language & $2.53(0.72)$ & $2.32(0.64)$ & $2.47(0.68)$ & $2.37(0.66)$ & 0.002 & $15.848^{* *}$ & 1.831 \\
\hline Rigidity personality & $3.01(0.59)$ & $3.01(0.52)$ & $3.04(0.62)$ & $3.08(0.51)$ & 2.002 & 0.348 & 0.162 \\
\hline Total score & $2.83(0.56)$ & $2.69(0.49)$ & $2.80(0.56)$ & $2.73(0.48)$ & 0.001 & $11.395^{*}$ & 1.398 \\
\hline \multicolumn{8}{|c|}{ Informant-report BAPQ } \\
\hline Aloof personality & $2.94(0.86)$ & $2.75(0.75)$ & $2.96(0.77)$ & $2.79(0.71)$ & 0.402 & $14.904^{* *}$ & 0.076 \\
\hline Pragmatic language & $2.61(0.81)$ & $2.38(0.70)$ & $2.71(0.85)$ & $2.52(0.77)$ & $7.022^{*}$ & $20.013^{* *}$ & 0.32 \\
\hline Rigidity personality & $3.16(0.73)$ & $3.11(0.57)$ & $3.28(0.70)$ & $3.25(0.59)$ & $10.975^{*}$ & 1.003 & 0.121 \\
\hline Total score & $2.91(0.66)$ & $2.75(0.53)$ & $2.98(0.61)$ & $2.86(0.54)$ & $7.278^{*}$ & $16.605^{* *}$ & 0.254 \\
\hline \multicolumn{8}{|l|}{ Best-estimate BAPQ } \\
\hline Aloof personality & $2.95(0.740$ & $2.75(0.65)$ & $2.92(0.65)$ & $2.77(0.59)$ & 0.031 & $20.27^{* *}$ & 0.498 \\
\hline Pragmatic language & $2.57(0.67)$ & $2.35(0.57)$ & $2.59(0.63)$ & $2.45(0.62)$ & 2.718 & $24.757^{* *}$ & 1.186 \\
\hline Rigidity personality & $3.09(0.55)$ & $3.06(0.46)$ & $3.16(0.54)$ & $3.16(0.45)$ & $8.593^{*}$ & 0.102 & 0.201 \\
\hline Total score & $2.87(0.54)$ & $2.72(0.43)$ & $2.89(0.49)$ & $2.79(0.43)$ & 2.793 & $18.943^{* *}$ & 0.917 \\
\hline
\end{tabular}


Table 3 Percentages of parents who met the criteria for BAP in the two parental groups

\begin{tabular}{|c|c|c|c|c|c|c|c|c|c|c|c|c|}
\hline & \multirow[b]{2}{*}{$\begin{array}{l}\text { Numbers } \\
\text { in PCA }\end{array}$} & \multicolumn{6}{|l|}{ Fathers } & \multicolumn{5}{|l|}{ Mothers } \\
\hline & & $\begin{array}{l}\text { Percentages } \\
\text { in PCA (\%) }\end{array}$ & Numbers in PTC & $\begin{array}{l}\text { Percentages } \\
\text { in PTC (\%) }\end{array}$ & $x^{2}$ & $p$-value & $\begin{array}{l}\text { Numbers } \\
\text { in PCA }\end{array}$ & $\begin{array}{l}\text { Percentages } \\
\text { in PCA (\%) }\end{array}$ & $\begin{array}{l}\text { Numbers } \\
\text { in PTC }\end{array}$ & $\begin{array}{l}\text { Percentages } \\
\text { in PTC (\%) }\end{array}$ & $x^{2}$ & $p$-value \\
\hline \multicolumn{13}{|l|}{ Self-report BAPQ } \\
\hline Aloof personality & 29 & 9.7 & 11 & 4 & 7.1 & 0.008 & 60 & 20.1 & 35 & 12.8 & 5.5 & 0.019 \\
\hline Pragmatic language & 56 & 18.7 & 23 & 8.4 & 12.8 & $<0.001$ & 75 & 25.1 & 55 & 20.1 & 2 & 0.153 \\
\hline Rigidity personality & 21 & 7 & 13 & 4.7 & 1.3 & 0.249 & 39 & 13 & 18 & 6.6 & 6.7 & 0.01 \\
\hline Total score & 27 & 9 & 10 & 3.6 & 6.9 & 0.009 & 87 & 29.1 & 48 & 17.5 & 10.6 & 0.001 \\
\hline \multicolumn{13}{|l|}{ Informant-report BAPQ } \\
\hline Aloof personality & 18 & 6 & 10 & 3.6 & 1.7 & 0.189 & 57 & 19.1 & 31 & 11.3 & 6.6 & 0.01 \\
\hline Pragmatic language & 59 & 19.7 & 28 & 10.2 & 10 & 0.002 & 76 & 25.4 & 43 & 15.7 & 8.2 & 0.004 \\
\hline Rigidity personality & 26 & 8.7 & 9 & 3.3 & 7.3 & 0.007 & 22 & 7.4 & 13 & 4.7 & 1.7 & 0.192 \\
\hline Total score & 33 & 11 & 13 & 4.7 & 7.7 & 0.006 & 64 & 21.4 & 28 & 10.2 & 13.3 & $<0.001$ \\
\hline \multicolumn{13}{|l|}{ Best-estimate BAPQ } \\
\hline Aloof personality & 24 & 8 & 6 & 2.2 & 9.8 & 0.002 & 63 & 21.1 & 35 & 12.8 & 6.9 & 0.008 \\
\hline Pragmatic language & 63 & 21.1 & 27 & 9.9 & 13.6 & $<0.001$ & 97 & 32.4 & 60 & 21.9 & 8 & 0.005 \\
\hline Rigidity personality & 19 & 6.4 & 8 & 2.9 & 3.8 & 0.053 & 23 & 7.7 & 12 & 4.4 & 2.7 & 0.098 \\
\hline Total score & 39 & 13 & 8 & 2.9 & 19.5 & $<0.001$ & 92 & 30.8 & 57 & 20.8 & 7.4 & 0.007 \\
\hline
\end{tabular}

BAP: Broad Autism Phenotype; BAPQ: Broad Autism Phenotype Questionnaire; PCA: parents of children with autism; PTC: parents of typically developing children.

parents of children with autism, mothers had higher BAP rates than fathers (all $p$ 's $<0.05$ ), except for the self-report and informant-report Pragmatic language subscales, and the informant-report and best-estimate Rigidity subscales. Among parents of typically developing children, mothers had higher BAP rates than fathers (all $p$ 's $<0.05$ ), except for the self-report, informantreport, and best-estimate Rigidity subscales and the informant-report Pragmatic language subscale.

\section{Co-occurrence of BAP features}

Co-occurrence was examined by comparing the percentage of parents with multiple BAP features for the three versions of the BAPQ in the two parent groups (i.e., parents of children with autism and parents of typically developing children). Figure 1 shows the proportion of fathers and mothers in the autism group and the typical development group with 0 to 4 BAP features. As indicated in Fig. 1, $9.4 \%$ of the fathers of children with autism had more than one BAP feature compared with $4.0 \%$ of fathers of typically developing children $\left(\chi^{2}=6.452, p=0.011\right)$ on the selfreport BAPQ. Moreover, $29.10 \%$ of mothers of children with autism had more than one BAP feature in contrast to $17.5 \%$ of mothers of typically developing children $\left(x^{2}=10.644, p=0.001\right)$. The parents (fathers and mothers) of children with autism also had higher rates of cooccurrence of BAP features on the other versions of the $\mathrm{BAPQ}$, than parents of typically developing children (all $p$ 's $<0.05$ ).

\section{Relationship between parental BAPQ scores and children} SRS total scores

Sixty-three children with autism and 63 typically developing children who were younger than four years old were excluded from this analysis because the SRS is not applicable for children under four years of age. There was no significant difference in age between the autistic $(\mathrm{M}=64.59$ months, $\mathrm{SD}=12.46)$ and the typically developing children $(M=64.08$ months, $S D=12.65)$. Children with autism had significantly higher SRS total scores $(M=98.93$, $\mathrm{SD}=25.35)$ than typically developing children $(\mathrm{M}=43.23$, $\mathrm{SD}=11.29 ; t=-30.532, p<0.001)$.

Regression analyses were conducted to examine the relationship between each BAPQ total score of each parent and their child's SRS total score. To check whether outliers were exerting influence on the regression results, the statistics such as residuals, leverage, and Cook's D were used. We found out that there were 21 outliers in autism group and 21 outliers in control group on self- and informant-report BAPQ. There were 23 outliers in autism group and 21 outliers in control group on best-estimate BAPQ. These outliers were excluded from this regression analysis. The results showed that fathers' and mothers' BAPQ total scores were significantly associated with their children's SRS total scores (Self-report BAPQ - fathers: Beta $=0.157, \quad p=0.002$; mothers: Beta $=0.194, p<0.001$; Informant-report BAPQ fathers: Beta $=0.212, \quad p<0.001$; mothers: $\operatorname{Beta}=0.089$, $p=0.084$; Best-estimate BAPQ - fathers: Beta $=0.173$, $p=0.004$; mothers: Beta $=0.16, p=0.007$ ). To investigate 

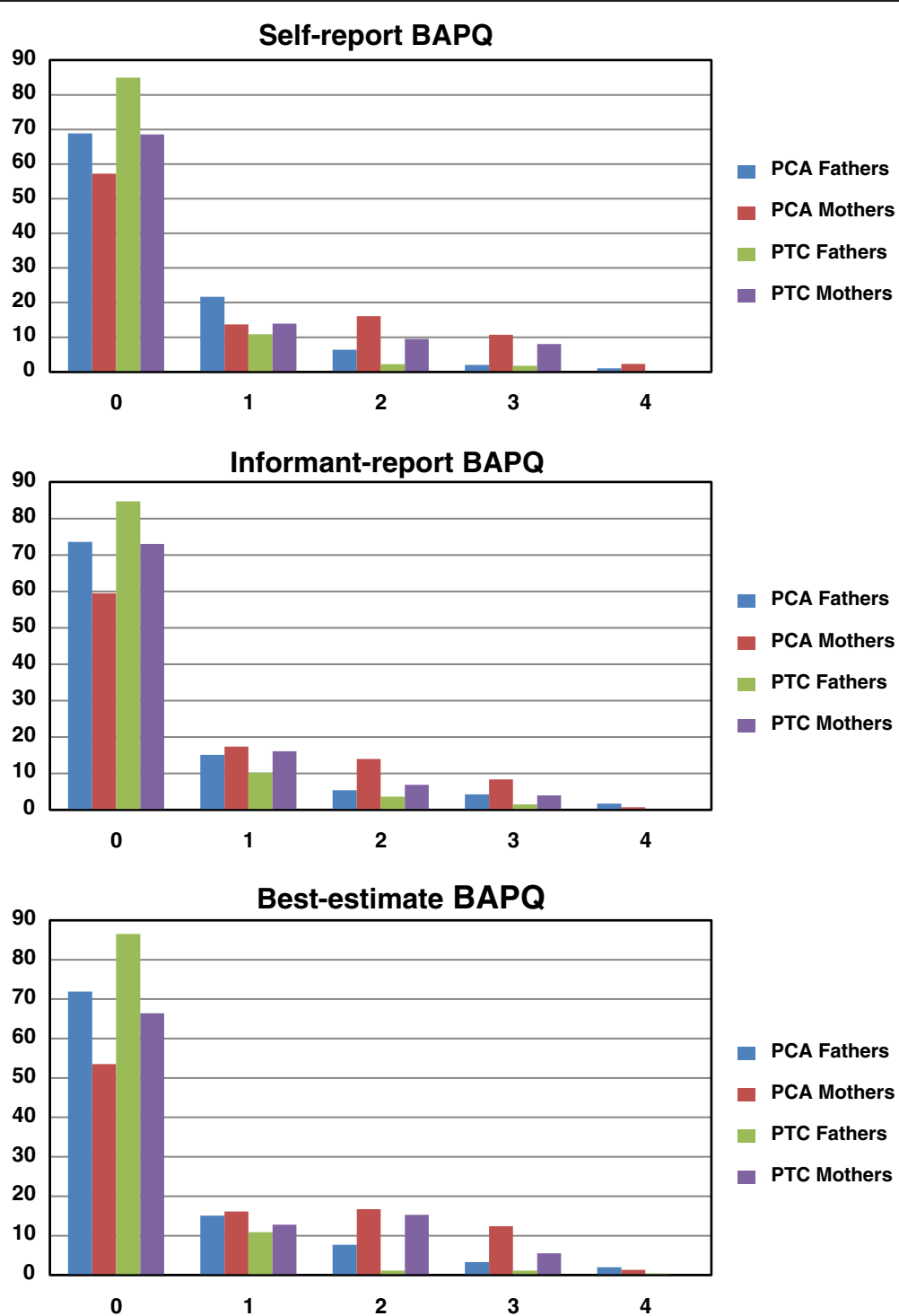

PCA Fathers
PCA Mothers
PTC Fathers
PTC Mothers

Fig. 1 Proportion of PCA and PTC fathers and mothers with $0,1,2,3$, and 4 BAP features on the three versions of the BAPQ. BAP: Broad Autism Phenotype; BAPQ: Broad Autism Phenotype Questionnaire; PCA: parents of children with autism; PTC: parents of typically developing children

Table 4 Results from regression analysis predicting children's SRS total scores from parental BAPQ total scores

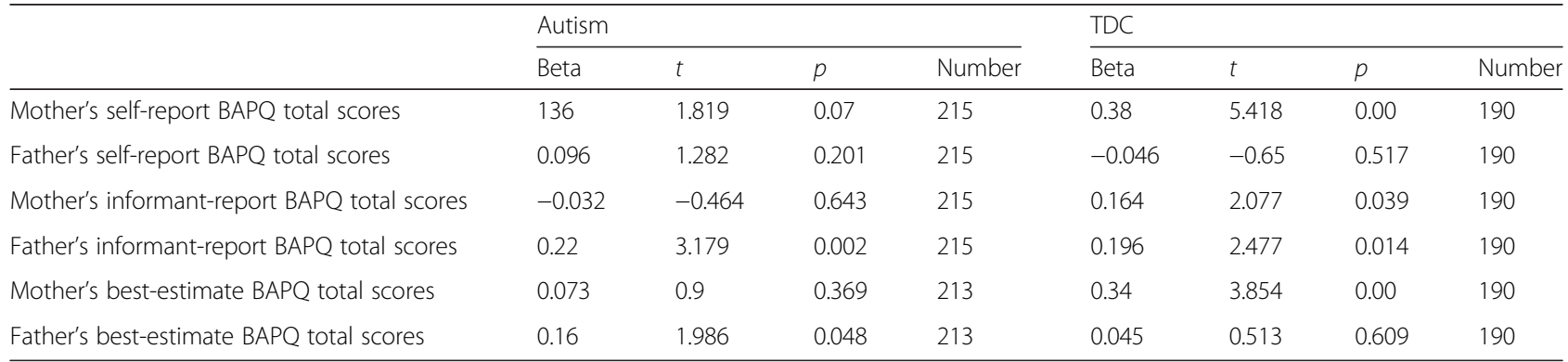

BAPQ: Broad Autism Phenotype Questionnaire; SRS: Social Responsiveness Scale; TDC: typically developing children. 
the differential effects of paternal and maternal BAPQ total scores on their child's social functioning, separate regression models were conducted for the autistic and control groups. We found that the three versions of BAPQ total scores of the mothers of children with autism were not significantly associated with their children's SRS total scores (see Table 4), whereas the three versions of BAPQ total scores of the mothers of typically developing children were significantly associated with their children's SRS total scores. The informant- and best-estimate BAPQ total scores of the fathers of children with autism were significantly associated with their children's SRS total scores, whereas the self- and best-estimate BAPQ total scores of the fathers of typically developing children were not significantly associated with their children's SRS total scores.

Parents were classified as "BAP present" if at least one parent met the criteria for BAP in at least one domain (Aloofness personality, Pragmatic language, Rigidity, or total score). Independent samples t-tests revealed that, in the autism group, children of "BAP present" parents had higher SRS total scores for the informant-report $(p=0.034)$ and best-estimate BAPQ $(p=0.004)$ than children of BAP absent" parents. In the typical development group, children with "BAP present" parents had higher SRS total scores for best-estimate BAPQ $(p=0.011)$ than children with "BAP absent" parents (Table 5).

\section{Discussion}

Both parents of children with autism in the present study had significantly higher total scores on all three versions of the BAPQ than parents of typically developing children. They also scored significantly higher on the Aloof personality and Pragmatic language subscales than parents of typically developing children. These findings are generally consistent with the earlier findings of Sasson and colleagues [13], which showed that PCA mothers and fathers had higher best-estimate scores on all the BAPQ subscales than control parents had. The current findings regarding sex differences in BAPQ scores did not support prior findings, which reported that the fathers of children with autism and males, in general, scored higher than females on BAP features $[7,14,21-24]$. Mothers in the current study had significantly higher scores than fathers on the informant-report Pragmatic language and the Rigidity subscales, and total score, as well as on the best-estimate Rigidity subscale. However, the mothers and fathers of children with autism did not differ significantly on any of their BAPQ scores. Robel et al. [25], who used a French version of the Autism Spectrum Quotient (AQ) to study French samples of parents of children with autism also failed to find sex differences between parents. Further research using another measure of BAP with a sample of Chinese parents of children with autism is needed to confirm this finding.

The percentages on parents with BAP features on each subscale and version of the BAPQ in our sample ranged from $7 \%$ to $32 \%$ among mothers of children with autism and from $4 \%$ to $22 \%$ among mothers of typically developing children. By comparison, Western studies have reported that $10 \%-23 \%$ [13] and $10 \%-12 \%$ [15] of mothers of children with autism have BAP features and $4 \%-10 \%$ [13], $1 \%-6 \%$ [15] of mothers of typically developing children have BAP features. The rate of BAP features ranged between $6 \%$ and $21 \%$ among fathers of children with autism and between $2 \%$ and $10 \%$ among fathers of children with typical development. These rates are generally consistent with Western studies, which have reported that roughly $13 \%-21.6 \%$ of fathers of children with autism and $4.7 \%-12.4 \%$ of fathers of typically developing children met the criteria for BAP [13, 15]. Mothers had higher BAP rates than fathers in our PCA group, which is inconsistent with Western studies, which have reported that a larger percentage of fathers than mothers met the criteria for BAP $[15,17,22,26]$. It is not known why the Chinese mothers have higher BAP rates, and further study is needed to determine whether cultural background leads to such discrepant rates, or whether the variation in rates are within the expected range of these BAP characteristics. The present study found parents of children with autism were more likely than parents of typically developing children to have more than one BAP feature. This finding is consistent with previous studies that reported biological parents of children with autism exhibit more BAP traits than other parents [13].

The BAP features of parents were associated with their child's social functioning among all the study participants,

Table 5 Mean SRS total scores in BAP absent and BAP present parents: autism and typically-developing children

\begin{tabular}{|c|c|c|c|c|c|c|c|}
\hline Group & BAPQ version & BAP absent number & SRS BAP absent & BAP present number & SRS BAP present & $\mathrm{t}$ & $p$ \\
\hline \multirow[t]{3}{*}{ Autism } & Self-report & 103 & $95.49(24.71)$ & 133 & $101.59(25.62)$ & -1.845 & 0.066 \\
\hline & Informant-report & 113 & $95.27(24.17)$ & 123 & $102.28(26.04)$ & -2.138 & 0.034 \\
\hline & Best-estimate & 105 & $93.66(24.69)$ & 131 & $103.15(25.18)$ & -2.904 & 0.004 \\
\hline \multirow[t]{3}{*}{ TDC } & Self-report & 128 & $42.16(11.08)$ & 83 & 44.89 (11.48) & -1.727 & 0.086 \\
\hline & Informant-report & 141 & $42.62(10.94)$ & 70 & $44.47(11.95)$ & -1.124 & 0.262 \\
\hline & Best-estimate & 138 & $41.80(11.31)$ & 73 & $45.93(10.83)$ & -2.559 & 0.011 \\
\hline
\end{tabular}

TDC: typically developing children; BAP: broad autism phenotype; BAPQ: Broad Autism Phenotype Questionnaire; SRS: Social Responsiveness Scale. 
but the patterns were different in the two groups of families. In the autism group, the informant-report and best-estimate BAP features of fathers were associated with their child's social functioning, but a similar association was not found for mothers. In contrast, an association was found in the typically developing children group between the BAP features of the mothers on the three BAPQ versions and their child's social functioning, but there was no association between the fathers' BAP features on selfreport and best-estimate BAPQ and their child's social functioning. This finding is consistent with previous Western studies [15, 27], which found the BAP traits of fathers were associated more strongly with their autistic children's social functioning than were the BAP traits of mothers. Autism has a strong genetic component, as indicated by the recurrence risk in families and in twin studies [28]. Previous studies have demonstrated that paternal and maternal genes are differentially expressed in offspring [29], and the differential expression is mediated by epigenetic modification [30, 31]. For example, the relative overexpression of paternal genes may drive cognition and behavior to "more demanding" phenotypes [32], as observed in Asperger syndrome [33]. Furthermore, some parent-of- origin genetic variants, such as some inherited copy-number variants $[34,35]$, are likely to contribute to the etiology of autism and, therefore, to lead to different effects on the phenotype of autistic children. Our findings provide evidence that the fathers of children with autism have an important influence on the severity of their child's autistic symptoms, and suggest that the genetic transmission is different in families with and without autism. In the autism group, paternal BAP features were associated with the child's social functioning in the informant-report and best-estimate BAPQ versions, but not in the selfreport $\mathrm{BAPQ}$. This may due to the fact that some fathers of children with autism lack insight into their BAP characteristics. In the typically developing children group, paternal BAP features were associated with the child's social functioning only in the informant-report BAPQ versions, but not in the self-report and best-estimate BAPQ, which highlights the importance of using best-estimate BAPQ versions to measure parental BAP features.

Several limitations of this study should be considered when interpreting the results reported here. First, although the diagnosis of autism in the children in the study was made according to the DSM-IV, it was not confirmed by the Autism Diagnostic Observation Schedule (ADOS) [36] or the Autism Diagnostic InterviewRevised (ADI-R) [37], because these two standard diagnostic tools are not commonly used in China at present. Second, we did not obtain other important information, such as the children's educational status and cognitive ability, or the parents' mental and physical health status, which may affect children's SRS scores and parental
BAPQ scores. For example, previous research has reported that parents of children with autism had greater stress and depression and a lower quality of life than parents of children with other developmental disabilities [38-40]. Thus, mental health status could affect the response of the parents of children with autism. Third, the total raw scores on the SRS, which usually should be converted to gender-based T-scores, were used directly for comparison in this study in the absence of Chinese norms. Fourth, we only used the BAPQ to measure the BAP features of parents, and a study conducted with another BAP measurement questionnaire is required to validate our results.

\section{Conclusions}

The current study increases our understanding of BAP and the relationship between parental BAP and children's social functioning in a different cultural context than that of most prior research. The most striking aspects of our work are that: (1) parents of children with autism had higher BAP rates than parents of typically developing children, and that mothers had higher BAP rates than fathers in both parental groups; and (2) the patterns of association between parental BAP and children's social impairment in autistic families is different from the pattern in families of children with typical development. The findings of our study have important implications for future genetic studies of autism, and may be applicable to some other neurodevelopmental and psychiatric disorders.

\section{Abbreviations}

BAP: Broad autism phenotype; BAPQ: Broad Autism Phenotype

Questionnaire; SRS: Social Responsiveness Scale; SCQ: Social Communication Questionnaire; DSM-IV: The Fourth Edition of the Diagnostic and Statistical Manual of Mental Disorders.

\section{Competing interests}

The authors declare that they have no competing interests.

\section{Authors' contributions}

$L S, J O, J Z$, and X.R.L conceived and designed the study. LS, JO, JG, SW, YZ and FZ performed the study. LS, JO and X.D.L analyzed the data. LS, JO, YZ and X.D.L wrote and revised the paper. All authors read and approved the final manuscript.

\section{Acknowledgements}

This study was supported by the Major State Basic Research Development Program of China (973 Program, No. 2012CB517901) and the Ministry of Health Science and technology industry special fund (No. 201302002) and Hunan Graduate student research innovation project (No. CX2013B117). The authors sincerely thank all participating children and their parents.

\section{Author details}

${ }^{1}$ Mental Health Institute of the Second Xiangya Hospital and Key Laboratory of Psychiatry and Mental Health of Hunan Province, The Central South University, 139 Middle Renmin Road, Changsha, Hunan, PR China. ${ }^{2}$ Traditional Chinese Medicine University of Hunan, Changsha, Hunan, PR China. ${ }^{3}$ Department of Neuroscience, The Third Affiliated Hospital of Soochow University, Changzhou, Jiangsu, PR China. ${ }^{4}$ Hangzhou Seventh People's Hospital, Hangzhou, PR China. ${ }^{5}$ Department of Psychiatry, Queen's University, 191 Portsmouth Ave, Kingston, ON K7M 8A6, Canada. 
Received: 21 July 2014 Accepted: 16 July 2015

Published online: 23 July 2015

\section{References}

1. American Psychiatric Association. Diagnostic and statistical manual of mental disorders: 4th edn., text revision (DSM-IV-TR). Washington, DC. American Psychiatric Publishing; 2000.

2. Ronald A, Hoekstra RA. Autism spectrum disorders and autistic traits: a decade of new twin studies. American journal of medical genetics Part B, Neuropsychiatric genetics : the official publication of the International Society of Psychiatric Genetics. 2011;156B(3):255-74.

3. Murdoch JD, State MW. Recent developments in the genetics of autism spectrum disorders. Curr Opin Genet Dev. 2013;23(3):310-5.

4. Geschwind DH. Genetics of autism spectrum disorders. Trends Cogn Sci. 2011;15(9):409-16.

5. Constantino JN, Lajonchere C, Lutz M, Gray T, Abbacchi A, McKenna $K$, et al. Autistic social impairment in the siblings of children with pervasive developmental disorders. Am J Psychiatry. 2006;163(2):294-6.

6. Rutter M. Genetic studies of autism: from the 1970s into the millennium. J Abnorm Child Psychol. 2000;28(1):3-14.

7. Smith CJ, Lang CM, Kryzak L, Reichenberg A, Hollander E, Silverman JM. Familial associations of intense preoccupations, an empirical factor of the restricted, repetitive behaviors and interests domain of autism. J Child Psychol Psychiatry. 2009;50(8):982-90.

8. Weiss LA. Autism genetics: emerging data from genome-wide copy-number and single nucleotide polymorphism scans. Expert Rev Mol Diagn. 2009;9(8):795-803.

9. de Geus EJ. Introducing genetic psychophysiology. Biol Psychol. 2002;61(1-2):1-10.

10. Gottesman II, Gould TD. The endophenotype concept in psychiatry: etymology and strategic intentions. Am J Psychiatry. 2003;160(4):636-45.

11. Bolton P, Macdonald H, Pickles A, Rios P, Goode S, Crowson M, et al. A case-control family history study of autism. J Child Psychol Psychiatry. 1994;35(5):877-900.

12. Dawson G, Estes A, Munson J, Schellenberg G, Bernier R, Abbott R. Quantitative assessment of autism symptom-related traits in probands and parents: Broader Phenotype Autism Symptom Scale. J Autism Dev Disord. 2007;37(3):523-36.

13. Sasson NJ, Lam KS, Childress D, Parlier M, Daniels JL, Piven J. The broad autism phenotype questionnaire: prevalence and diagnostic classification. Autism research : official journal of the International Society for Autism Research. 2013;6(2):134-43.

14. Sasson NJ, Lam KS, Parlier M, Daniels JL, Piven J. Autism and the broad autism phenotype: familial patterns and intergenerational transmission. J Neurodev Disord. 2013;5(1):11.

15. Maxwell CR, Parish-Morris J, Hsin O, Bush JC, Schultz RT. The broad autism phenotype predicts child functioning in autism spectrum disorders. J Neurodev Disord. 2013;5(1):25.

16. Gau SS-F, Liu L-T, Wu Y-Y, Chiu Y-N, Tsai W-C. Psychometric properties of the Chinese version of the social responsiveness scale. Research in autism spectrum disorders. 2013;7(2):349-60.

17. Hurley RS, Losh M, Parlier M, Reznick JS, Piven J. The broad autism phenotype questionnaire. J Autism Dev Disord. 2007;37(9):1679-90.

18. Constantino JN, Davis SA, Todd RD, Schindler MK, Gross MM, Brophy $\mathrm{SL}$, et al. Validation of a brief quantitative measure of autistic traits: comparison of the social responsiveness scale with the autism diagnostic interview-revised. J Autism Dev Disord. 2003;33(4):427-33.

19. Constantino JN, Hudziak JJ, Todd RD. Deficits in reciprocal social behavior in male twins: evidence for a genetically independent domain of psychopathology. J Am Acad Child Adolesc Psychiatry. 2003;42(4):458-67.

20. Reiersen AM, Constantino JN, Volk HE, Todd RD. Autistic traits in a populationbased ADHD twin sample. J Child Psychol Psychiatry. 2007;48(5):464-72.

21. Seidman I, Yirmiya N, Milshtein S, Ebstein RP, Levi S. The Broad Autism Phenotype Questionnaire: mothers versus fathers of children with an autism spectrum disorder. J Autism Dev Disord. 2012;42(5):837-46.

22. Wheelwright S, Auyeung B, Allison C, Baron-Cohen S. Defining the broader, medium and narrow autism phenotype among parents using the Autism Spectrum Quotient (AQ). Molecular autism. 2010;1(1):10.
23. Bishop DV, Maybery M, Maley A, Wong D, Hill W, Hallmayer J. Using self-report to identify the broad phenotype in parents of children with autistic spectrum disorders: a study using the Autism-Spectrum Quotient. J Child Psychol Psychiatry. 2004;45(8):1431-6.

24. Murphy M, Bolton PF, Pickles A, Fombonne E, Piven J, Rutter M. Personality traits of the relatives of autistic probands. Psychol Med. 2000;30(6):1411-24.

25. Robel L, Rousselot-Pailley B, Fortin C, Levy-Rueff M, Golse B, Falissard B. Subthreshold traits of the broad autistic spectrum are distributed across different subgroups in parents, but not siblings, of probands with autism. Eur Child Adolesc Psychiatry. 2014;23(4):225-33.

26. Davidson J, Goin-Kochel RP, Green-Snyder LA, Hundley RJ, Warren Z, Peters SU. Expression of the broad autism phenotype in simplex autism families from the Simons Simplex Collection. J Autism Dev Disord. 2014;44(10):2392-2399.

27. Klusek J, Losh M, Martin GE. Sex differences and within-family associations in the broad autism phenotype. Autism : the international journal of research and practice. 2014;18(2):106-16.

28. Devlin B, Scherer SW. Genetic architecture in autism spectrum disorder. Curr Opin Genet Dev. 2012;22(3):229-37.

29. Day T, Bonduriansky R. Intralocus sexual conflict can drive the evolution of genomic imprinting. Genetics. 2004;167(4):1537-46.

30. de la Casa-Esperón E, Sapienza C. Natural selection and the evolution of genome imprinting. Annu Rev Genet. 2003;37(1):349-70.

31. Flashner BM, Russo ME, Boileau JE, Leong DW, Gallicano GI. Epigenetic factors and autism spectrum disorders. Neuromolecular Med. 2013;15(2):339-50.

32. Haig D. Genomic imprinting and kinship: how good is the evidence? Annu Rev Genet. 2004;38:553-85.

33. Baron-Cohen S, Belmonte MK. Autism: a window onto the development of the social and the analytic brain. Annu Rev Neurosci. 2005;28:109-26.

34. Delahanty RJ, Kang J, Brune CW, Kistner EO, Courchesne E, Cox NJ, et al. Maternal transmission of a rare GABRB3 signal peptide variant is associated with autism. Mol Psychiatry. 2011;16(1):86-96.

35. Girirajan S, Rosenfeld JA, Coe BP, Parikh S, Friedman N, Goldstein A, et al. Phenotypic heterogeneity of genomic disorders and rare copy-number variants. N Engl J Med. 2012;367(14):1321-31.

36. Lord C, Risi S, Lambrecht L, Cook Jr EH, Leventhal BL, DiLavore PC, et al. The autism diagnostic observation schedule-generic: a standard measure of social and communication deficits associated with the spectrum of autism. J Autism Dev Disord. 2000;30(3):205-23.

37. Lord C, Rutter M, Le Couteur A. Autism Diagnostic Interview-Revised: a revised version of a diagnostic interview for caregivers of individuals with possible pervasive developmental disorders. J Autism Dev Disord. 1994;24(5):659-85.

38. Sanders $J$, Morgan SB. Family stress and adjustment as perceived by parents of children with autism or Down syndrome: Implications for intervention. Child \& Family Behavior Therapy. 1997;19(4):15-32.

39. Dabrowska A, Pisula E. Parenting stress and coping styles in mothers and fathers of pre-school children with autism and Down syndrome. J Intellect Disabil Res. 2010;54(3):266-80.

40. Olsson MB, Hwang C. Depression in mothers and fathers of children with intellectual disability. J Intellect Disabil Res. 2001;45(6):535-43.

\section{Submit your next manuscript to BioMed Central and take full advantage of:}

- Convenient online submission

- Thorough peer review

- No space constraints or color figure charges

- Immediate publication on acceptance

- Inclusion in PubMed, CAS, Scopus and Google Scholar

- Research which is freely available for redistribution

Submit your manuscript at www.biomedcentral.com/submit

C) Biomed Central 